\title{
LARYNGOSCOPE BLADE WITH SUCTION UNIT
}

\author{
J.K. MAZumder
}

DIRECT LARYNGOSCOPY under general anaesthesia or under topical analgesia of the upper airway is used routinely to facilitate tracheal intubation. It is sometimes necessary to delay insertion of the tracheal tube while the right hand manipulates a suction device. This being so, it seemed expedient to incorporate a suction device in the laryngoscope blade, leaving the right hand free for the intubation manoeuvre.

\section{DESCRIPTION}

The design of the "Laryngoscope Blade with Suction Unit" is based on the conventional Macintosh curved blade (Figure). A metal suction tube is fixed into the groove on the posterior aspect of the Macintosh blade so that the tip just protrudes behind the end of the blade on its left side. When so positioned, the suction tip can not injure the pharyngeal mucosa and the view of the karynx is unobstructed. This blade can be manoeuvred inside the mouth in the same way as the normal blade without the suction attachment. This prototype was constructed in our hospital workshop.

\section{Discussion}

More than 60 laryngoscope blades have been introduced since Kirstein reported his experience with the autoscope, ${ }^{2,3}$ Some modified blades have special attachments to facilitate intubation. ${ }^{5}$ One modified blade has previously been described specifically for tracheobronchial suction in the newborn ${ }^{4}$ but the catheter is placed in front of a straight blade and interferes with visualization of the larynx.

My colleagues and I have used the "Laryngoscope Blade with Suction Unit" as described and found it offers advantages both where pharyngeal secretions are present or when there is blood in the pharynx, as from a bleeding tonsillar bed.

J.K. Mazumder, M.B., B.S., F.F.A.R.C.S., Department of Anaesthesia, Montreal General Hospital, Montreal, Quebec, H3G IA4.

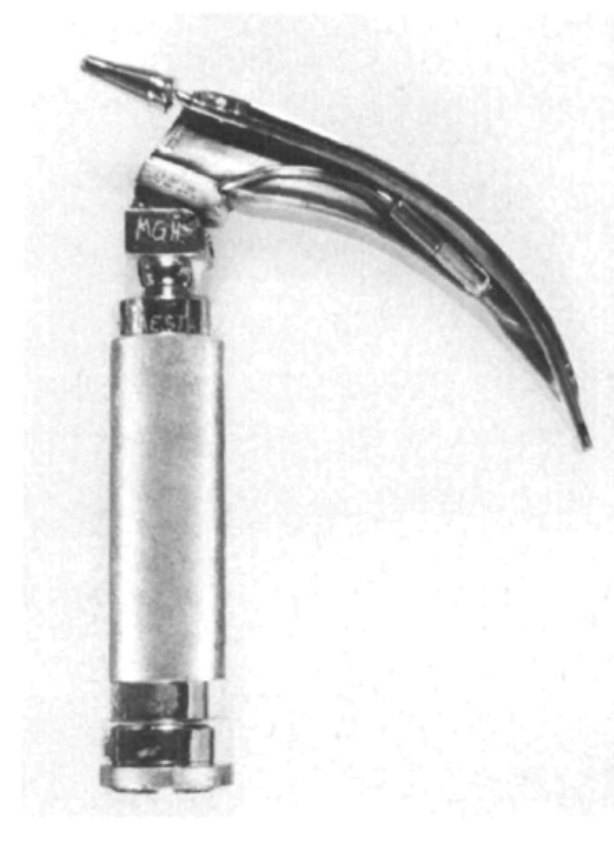

SUMmary

A laryngoscope blade incorporating a suction tube is described. Blood or secretions are automatically aspirated from the pharynx when the blade is inserted.

\section{RÉSUMÉ}

Une canule d'aspiration fixée à une lame de laryngoscope courbe, permet laspiration automatique des secrétions lorsque le laryngoscope est introduit. L'auteur en explique le fonctionnement.

\section{ACKNOWLEDGEMENTS}

I am grateful to Dr Ian Metcalf, Acting Director of Anaesthesia and Dr A.J.C. Holland who inspired me to write this article. 


\section{REFERENCES}

I. Macintosh, R.R. A new laryngoscope. Lancet / 205 (1943).

2. Kirstein, A Autoskopie des Larynx und der Trachea. Woehenscher 32: 476-478 (1895).

3. WEEKS, D.B. Anaesthesiology 40:200-1 (1974).
4. EMERSON. E.B. Catheterizing laryngoscope for trachobronchial aspiration of newborn and premature infants. Am. J. Obs. \& Gyn. 63: 1374-76 (1952).

5. Grant, G.C. A new laryngoscope, anaesthesia and intensive care 5: 263-4 (1977). 